\title{
ROMARIA DAS ÁGUAS: ENTRE PRÁTICAS RELIGIOSAS E PRÁTICAS ECOLÓGICAS NO RIO GRANDE DO SUL
}

\author{
Stella Maris Nunes Pieve ${ }^{1}$
}

\section{Introdução}

Este trabalho propõe uma reflexão sobre as formas de sociabilidade, interação e conflitos que configuram a prática religiosa ritual dos peregrinos da Romaria das Águas no Lago Guaíba. A proposta é entender como as pessoas experienciam essa peregrinação e a relacionam com outras práticas da vida cotidiana, especificamente, a relação entre ecologia e religião. Os dados apresentados baseiam-se nas primeiras observações para minha tese de doutorado, na $17^{\mathrm{a}}$ Romaria das Águas 2010 e a Celebração das Águas 2010, esta última promovida pelo Comitê de Gerenciamento da Bacia Hidrografica do Rio dos Sinos (COMITESINOS) na Universidade do Vale do Sinos (UNISINOS). Cabe salientar que a Celebração não se opõe à Romaria das Águas, mas particulariza o ritual para a Bacia Hidrográfica do Rio dos Sinos.

Tanto a Romaria das Águas como a Celebração das Águas são rituais compostos por dois momentos: 1) a coleta de "águas limpas" - em nascentes, rios e arroios e 2) a mistura e benção dessas águas para serem lançadas às "águas sujas" do rio ou lago em questão. Até o presente momento, durante a $17^{\mathrm{a}}$ Romaria das Águas foi possível acompanhar a coleta de água das nascentes, uma Ação Coletiva na Ilha Grande dos Marinheiros $^{2}$ e os rituais de mistura das águas, tanto no Lago Guaíba, quanto no Lago da Unisinos. A partir dessas experiências consegui contatar alguns organizadores e participantes da Romaria das Águas, especialmente representantes religiosos. Na Celebração das Águas, acompanhei o ritual de benção e mistura das águas e ao final pude conversar com a secretária executiva do COMITESINOS e uma das organizadoras do evento. Cabe ressaltar que Irmão Cechin é figura central no evento, tendo participado dos dois. É considerado o criador da Romaria.

A procissão que acontece por água é por terra, é organizada por católicos, afroumbandistas, evangélicos, prefeituras, escolas e $\mathrm{ONG}^{\prime} \mathrm{s}$ em torno do cuidado com o Lago Guaíba. O trabalho começa com a coleta de águas nas nascentes do Lago, acompanhada de plantio de mudas de árvores nativas pelas escolas, encontros de

\footnotetext{
${ }^{1}$ Universidade Federal do Rio Grande do Sul, Brasil.

${ }^{2}$ A Ação Social consiste na realização gratuita de serviços de saúde, responsabilidade social, educação, lazer e estática (FAUERS, 2010).
} 
educação ambiental junto com prefeituras e culmina na procissão de Nossa Senhora Aparecida das Águas, no dia 12 de outubro até a Usina do Gasômetro. Neste dia e local é realizada uma celebração inter-religiosa e o ritual de jogar as "águas limpas" das nascentes nas "águas sujas” do curso do rio, em um ato simbólico de despoluição do lago.

Para o desenvolvimento deste trabalho me apoio na "sociologia das formas" de George Simmel (1983) ao tentar entender os rearranjos sociais envolvidos na sobreposição das práticas ecológicas e religiosas, e na "sensibilidade coletiva" de Michel Maffesoli (2000) para dar conta da compreensão do vivenciar ou sentir comum, a "aura estética" que remetem a uma pulsão comunitária. Ainda, entendendo-se as práticas sociais como práticas nas quais o sujeito se insere e opera conjuntamente com aspectos subjetivos e objetivos, me utilizo do conceito de habitus de Pierre Bourdieu (1983) e de Norbert Elias (1994), entendendo o habitus ecológico como a camada proeminente na orientação do habitus social do grupo em questão.

É importante destacar que Isabel Cristina de Moura Carvalho e Carlos Alberto Steil (2009) discutem a formação de uma subjetividade ecológica constituída como um habitus no processo de subjetivação de um campo de preocupações ambientais em relação às práticas pedagógicas da educação ambiental a partir de um referencial teórico ligado à filosofia da percepção (Merleau-Ponty), antropologia fenomenológica (Thomas Csordas) e epistemologia ecológica (Tim Ingold), no intuito de evidenciar as dicotomias não superadas da prática.

\section{Um breve histórico da Romaria das Águas}

A Romaria das Águas teve início na década de 1990 na Ilha Grande dos Marinheiros, Arquipélago de Porto Alegre. O marco principal foi a falta de água potável nas Ilhas devido à poluição do Lago. Rodeadas de água e dependendo de carros pipas para obterem água potável, mulheres que se reuniam no Clube de Mães da referida Ilha resolveram se organizar para reciclar lixo e, consequentemente, contribuir com a despoluição do Guaíba (Pacheco, Soares e Pavelacki, 2008). Paralelamente a este movimento, o Clube de Mães, tinha uma ação política de cuidar de crianças, distribuir sopa à população carente e de buscar cursos e atividades de trabalho e geração de renda que pudessem inserir as mães participantes dali.

É importante destacar que esse trabalho político-religioso no bairro Arquipélago de Porto Alegre, especialmente da Igreja Católica, tem base na Teologia da Libertação e 
seus princípios de “opção pelos pobres”. Daí iniciam-se as ações com as Comunidades Eclesiais de Base (CEBs) na periferia da Região Metropolitana de Porto Alegre, como Canoas, nos anos 1970 e derivam para as atividades com catadores de materiais recicláveis nos anos 1980 em diante.

Assim, durante o trabalho de separação dos materiais, essas mulheres encontraram uma imagem de Nossa Senhora Aparecida quebrada. Esse encontro, associado à Teologia da Libertação e aos "milagres da ordem do cotidiano", remetem a essas mulheres uma analogia da imagem quebrada à Nossa Senhora Aparecida, padroeira do Brasil, também encontrada quebrada em Guararema, SP, por pescadores que precisavam de ajuda em seu trabalho. Nesta ocasião a imagem foi restaurada por essas mulheres e o encontro associado à atenção da Santa às condições de suas vidas, mulheres, trabalhadoras, sofredoras e sem água. Pensando na incoerência da falta de água em uma Ilha em que só chegava lixo, a Santa foi "batizada" de Nossa Senhora das Águas e até hoje encontra-se no clube de Mães.

E em 1994 acontece a primeira peregrinação na Ilha Grande dos Marinheiros, já iniciando a Romaria das Águas. Neste mesmo ano é fundada a Organização Não Governamental Devoção de Nossa Senhora Aparecida com auxílio de Irmão Cechin. De caráter religioso e social, tal ONG tem como objetivo reverter a poluição do Lago Guaíba e implantar o monitoramento participativo dos rios que compõem a Bacia Hidrográfica do Guaíba. As primeiras procissões da Romaria das Águas eram apenas na Ilha Grande dos Marinheiros e contava com uma procissão fluvial entre o Delta do Jacuí e Lago Guaíba. Ao envolverem mais instituições como ONGs, Projetos Sociais, Escolas, poder público, Comitês de Bacias e escolas, os rituais de coleta começaram a se expandir para as nascentes dos rios da Bacia do Guaíba. Em 1999, passa a fazer parte da Romaria toda a Bacia Hidrográfica do Lago Guaíba (Romaria das Águas, 2010).

O Comitê de Gerenciamento da Bacia Hidrográfica do Rio dos Sinos (COMITESINOS) se torna parte do movimento em 2002, convergindo suas ações com a Romaria das Águas das Ilhas em um primeiro momento, pois durante alguns anos houve investimentos do Governo Estadual para sua realização da procissão. Todavia tais recursos foram se esgotando e de acordo com a Secretária Executiva do referido órgão, chegaram as "vacas magras". De acordo com ela, as "vacas gordas" envolviam coletas de água, plantio de mudas nativas e cultos inter-religiosos in situ, ou seja, nas nascentes que compõem a Bacia do Rio dos Sino - Caraá, Santo Antônio da Patrulha, Taquara, São Francisco de Paula, Três Coroas, Parobé, Sapiranga, Estância Velha, Novo 
Hamburgo, São Leopoldo, Sapucaia, Esteio e Canoas. Atualmente, sem investimentos o COMITESINOS sempre celebra a ocasião da maneira que pode, em 2010, por exemplo, um representante de cada nascente trouxe sua amostra de água até a UNISINOS.

\section{Formas de Sociabilidade: convivência e conflito nos diferentes "rituais da Água"}

Como já enunciado anteriormente, tanto a Romaria quanto a Celebração das Águas são movimentos que sobrepõem práticas ecológicas e religiosas, e a partir destas proporcionam uma relação de interação entre os campos da religião, da ecologia, da política e da educação via diferentes formas de socialização. A $17^{a}$ Romaria das Águas 2010 aconteceu entre agosto e outubro e contou com a participação de Secretarias e Coordenadorias de Prefeituras de Porto Alegre e das cidades onde se fez presente, assim como todas as coletas contaram com um culto inter-religioso, abrangendo a Umbanda, a Igreja Católica e Igrejas Evangélicas - Messiânica e Comunidade Baha'i. Já a Celebração das águas 2010 envolveu escolas municipais, Organizações Não Governamentais, Poder Público Municipal e líderes religiosos da Umbanda,Igreja Católica e Igreja Luterana para a celebração de um culto macro-religioso no evento.

Esta configuração denota que existe uma proposta motivadora de união dos interesses e dos objetivos desses indivíduos que possibilita a constituição de um processo de sociação, como sugerido por George Simmel (1983), a proteção ambiental das águas, a despoluição destas, ou seja, o aspecto ecológico, evidenciado especialmente, no principal ritual de ambos eventos, o ritual que fecha a peregrinação, o ato simbólico de jogar as águas das nascentes, as "águas limpas" misturadas e abençoadas nas águas do curso do lago, nas “águas sujas” do Guaíba ou da Unisinos, pretendendo uma despoluição ou o seguimento do curso natural destas.

É neste sentido, que sem perder de vista que para George Simmel (1983) o conflito é também um importante fator de interação, as próximas seções ao descreverem em parte os dois eventos em questão, pretendem abordar a peregrinação e os rituais que os acompanham como formas de socialização que se manifestam a partir de seus conteúdos políticos, religiosos e ecológicos.

\section{A $17^{\mathrm{a}}$ Romaria das Águas 2010}

A peregrinação da $17^{\mathrm{a}}$ Romaria das Águas 2010 foi organizada majoritariamente pela Federação Afro-Umbandista e Espiritualista do Rio Grande do Sul (FAUERS) e percorreu $2810 \mathrm{~km}$ do estado, passando por nove municípios dos quais foram trazidas 
amostras de águas de onze nascentes de rios e/ou arroios. Tal peregrinação seguiu um calendário de atividades que além da coleta de águas incluiu um mutirão de limpeza e o plantio de mudas nativas no Arroio Araçá em Canoas, a Ação Social da Umbanda na Ilha Grande dos Marinheiros e a "visita" da imagem de Nossa Senhora Aparecida das Águas de, aproximadamente, $1,80 \mathrm{~m}$ de altura em Casas de Caridade, Centros Espiritualistas e Templos da Umbanda, em Igrejas e Paróquias Católicas, na Prefeitura de Canoas, na Casa de Cultura de Esteio e nas praças centrais de Alvorada e Viamão.

Destes eventos, pude acompanhar a "Coleta na Nascente do Arroio Araçá/Fonte Dona Josefina", em Canoas, onde estiveram presentes indivíduos de diferentes religiões - umbandistas, católicos e evangélicos, membros da Comunidade Bahá'í e da Igreja Messiânica -; de diferentes localidades, como Porto Alegre e Alvorada; e de órgãos da Prefeitura Municipal de Canoas - Secretaria Municipal de Desenvolvimento Social, Coordenadoria de Diversidade e Secretaria do Meio Ambiente. Todos presentes, o primeiro passo do evento é uma apresentação dos presentes no ritual de coleta.

O primeiro momento do evento trouxe um pouco da história da Fonte Dona Josefina, que há pouco foi revitalizada. Bastante lembrado que na Romaria das Águas de 2009, a coleta ali foi um "pedido de socorro" pelo não aterro deste olho d'água, em 2010 é evidenciado que a Fonte está protegida e o espaço ao seu redor transformado em área de lazer, um campo de futebol e uma praça. Conversando com Inês, que é membro da FAUERS, funcionária da Secretaria de Desenvolvimento Social e uma das representantes do Projeto Arroio Araçá, tomo consciência de que além de uma reverência religiosa pela proteção das nascentes, há também uma interação social, que reivindica a preservação ambiental desses espaços. A Fonte Josefina em 2010, por exemplo, foi revitalizada pela Prefeitura Municipal de Canoas via intervenção dos projetos "Arroio Araçá" e "Revitalizando Fontes de Vida", cujos seus representantes também participam da Romaria e/ou da Celebração das Águas.

Para a coleta propriamente dita, os representantes religiosos formam um semicírculo em frente a pequena imagem ${ }^{3}$ de Nossa Senhora das Águas, que se encontra sobre o arco de tijolos que protege a fonte. A responsável pelo projeto de revitalização da Fonte, uma professora membro da coordenadoria da FAUERS, é quem coleta a água num cálice transparente, enquanto uma moça grávida lhe joga pétalas de rosas e nós cantamos pontos de Umbanda. É preciso curvar metade do corpo para dentro da fonte e

\footnotetext{
${ }^{3}$ Cabe aqui ressaltar que neste momento ainda não está presente a imagem "grande" de Nossa Senhora das Águas, pois estava em reforma.
} 
quando ela sai e apresenta o cálice com água é aplaudida.

Água coletada, são feitas e distribuídas as bênçãos. Reza-se um Pai Nosso da Umbanda, uma Ave Maria da Igreja Católica, uma oração messiânica e um Pai Nosso da Comunidade Bahá'í. Cânticos predominantemente umbandistas e católicos mediados por tambores são entoados tanto à Oxum, quanto à Iemanjá e à Nossa Senhora Aparecida. A cerimônia acaba com uma benção feita por Ir. Cechin que abençoa e benze a todos com um ramo de aroeira e água da fonte. No próximo final de semana a esta peregrinação, a imagem de 1,80 de Nossa Senhora Aparecida das Águas, que estava sendo reformada, chegou e passou a compor o ritual, "peregrinando e dormindo" nas nove cidades já mencionadas.

Essas formas de convivência me remetem às interações de "uns-com-os-outros" e "uns-pelos-outros" constituinte da sociedade e das relações inter-humanas propostas por George Simmel (1983, p.21). Mas sem esquecer as relações "contra-os-outros", ao final do evento, a partir de conversas informais começo a me dar conta de conflitos latentes. Por exemplo, o conflito declarado pelo pastor da Igreja Messiânica que nos conta que a imagem de Nossa Senhora das Águas não condiz com a realidade de sua Igreja, pois por serem de raiz oriental, nem todos os dragões significam o "mal", mas também a sabedoria. Na visão dele, para que este dragão simbolize o mal, precisa ser preto, não verde como é atualmente representado.

Outro momento importante de conflito foi a restauração da imagem de Nossa Senhora Aparecida das Águas. Patrocinada pela FAUERS, o lançamento da imagem restaurada se deu no mesmo dia em que ela peregrinou até Canoas, depois da Ação Social também promovida pela FAUERS na Ilha Grande dos Marinheiros. Assim, Nossa Senhora Aparecida das Águas passou todo dia exposta na Escola Alvarenga Peixoto, enquanto os moradores da Ilha recebiam atendimento médico, odontológico, alimentação, tratamento de beleza e entretenimento para no fim do dia peregrinar até Canoas e dali em diante até São Pedro do Sul, retornando no dia 12 de outubro pela manhã. Tal fato, embora não gerando um conflito direto, gerou "burburinhos". De acordo com os participantes do evento, "a santa, que nunca tinha saído da Ilha, agora o lugar que ela menos fica é na Ilha”.

Ademais, nesses encontros são comuns discursos que unificam e legitimam a união de todos pela ecologia, como "ninguém quer falar da religião, mas do nosso bem maior que é a água", ou "a natureza e a ecologia são a bandeira dos religiosos", ainda "agredir a natureza é agredir a todos nós", bem como o slogan da FAUERS "a natureza 
é o altar de todos nós". Até mesmo Nossa Senhora Aparecida das Águas, por vezes é chamada de Rainha da Ecologia, associando a devoção de diferentes ordens, mais do que zelar pelos pobres, Nossa Senhora Aparecida das Águas zela pelos pobres que zelam pela natureza. Sob essa perspectiva, existe um esforço dos diferentes grupos que compõem a romaria em unificar suas celebrações e reivindicações na esfera da ecologia, tornando esta uma "linguagem comum", entre si.

Nos discursos e práticas que os acompanham, as diferenças, embora respeitadas, não deixam de ser ressaltadas. Os mesmos discursos destacam a "união de vibrações inter-religiosas" no evento, a Rainha da Ecologia, sempre que possível também é destacada como Nossa Senhora Aparecida das Águas, Mãe Oxum e até mesmo Iemanjá, e as águas são abençoadas pelas diferentes lideranças religiosas sob suas diferentes preces, é comum ouvir um Pai Nosso, uma Ave Maria e orações particulares. Tambores, pontos, guias e vestes brancas, violão, cânticos, imagens de Nossa Senhora Aparecida e hábitos também marcam essas diferenças.

Tendo em vista que o conflito não é de todo negativo, ao contrário, faz parte da interação (Simmel, 1983), no dia 12 de outubro nos reencontramos todos para o principal ritual da Romaria, a benção e mistura das "águas limpas" nas "águas sujas" do Lago Guaíba. Em 2010, o evento contou com dois momentos. Pela manhã a chegada de Nossa Senhora Aparecida das Águas na Ilha Grande dos Marinheiros e sua procissão fluvial até a Usina do Gasômetro, e pela tarde o culto inter-religioso, a benção e a mistura das águas no Guaíba. Na Ilha Grande dos Marinheiros, a dinâmica relembrou um pequeno histórico da Romaria. A imagem de Nossa Senhora Aparecida "colada" pelas mulheres recicladoras esteve presente, apresentaram-se de grupos locais e visitantes de Umbanda e de projetos sociais - como a bateria do Carnaval Comunitário da Ilha da Pintada, o teatro de bonecos do Departamento Municipal de Água e Esgoto (DMAE). Ao lado do palco havia um altar para Nossa Senhora Aparecida das Águas. E espalhadas no espaço algumas bancas de venda de alimentos e artesanatos da Ilha.

Terminado o evento na Ilha, seguimos até a Ilha do Pavão para embarcar na procissão até o Gasômetro. A maior parte dos romeiros ocuparam o barco "Noiva do

\footnotetext{
${ }^{4}$ Termo cunhado por Edmund Leach em 1954, (1996) que sugere que o ritual é uma forma de afirmação simbólica, uma forma de adquirir e perpetuar o conhecimento socialmente adquirido, já que é ele que permite que os diferentes propósitos em jogo sejam entendidos por todos seus participantes. Reflexão também apoiada nos textos de Mariza Peirano (2002) e de Christine de Alencar Chaves (2002) para entender ritual como um ato de sociedade que revela as visões de mundo dos grupos em questão, tendo em vista que estes eventos ampliam, acentuam e sublinham o que é comum entre eles.
} 
Caí", enquanto Nossa Senhora Aparecida das Águas esteve num barco menor ao lado. Também nos segue um pequeno barco de pescadores e um maior de fiéis. Cruzamos o Rio Jacuí, o Guaíba e fomos até o Gasômetro, de longe percebe-se muita gente no evento. Ao desembarcarmos formamos um longo corredor de pessoas com as mãos dadas, que vai das proximidades da água até o palco para Nossa Senhora "passar" pelo meio, ela passando se desfaz o corredor e seguimos atrás dela até o palco.

A imagem permaneceu em frente do palco, um pouco abaixo dele. Foi narrda a história da Romaria das Águas; representantes religiosos - Igreja Católica, Umbanda, Igreja Messiânica - fizeram suas falas, novamente ligando Ecologia e Religião; lideranças religiosas afro-umbandistas fizeram um relato sobre a peregrinação pelo estado. Uma mesa decorada com flores e uma pequena imagem de Nossa Senhora Aparecida ampara o cálice onde serão despejadas as águas, são chamados representantes das coletas para "misturarem" suas "águas limpas" nesse cálice. Vieram amostras de água de onze lugares - Sapucaia, Canoas, Alvorada, Viamão, Gravataí, Porto Alegre zona Sul, zona leste e Arquipélago -, Rio Pardo, Santa Maria e da nascente do Ibicuí, principal afluente do Rio Uruguai. Essas águas são abençoadas pelos líderes religiosos.

Em seguida, duas gestantes foram convocadas para fazerem o ritual de mistura. Uma de cada lado da mesa vestem túnicas brancas e expõem seus ventres, é lido um Pai Nosso Ecológico e saímos em procissão com o cálice até o bar flutuante de onde as “águas limpas” são lançadas nas "águas sujas” do Guaíba. Voltamos ao palco, Nossa Senhora das Águas permanece um pouco para que fiéis possam deixar seus pedidos. Ano passado, uma das reclamações do evento foi de que devido a rapidez que a Santa retornou à Ilha Grande dos Marinheiros, não deu tempo de seus devotos fazerem pedidos, orações e rezas. Em seguida, Nossa Senhora Aparecida das Águas retorna em mais uma procissão ao barco pelo qual é levada de volta à Ilha Grande dos Marinheiros. É interessante notar que gestantes marcam presença no evento, pois representam "a vida, a renovação da vida e sua continuidade".

\section{A Celebração das Águas 2010}

A Celebração das Águas do COMITESINOS ocorreu no dia 5 de outubro do corrente ano na Universidade do Vale do Rio dos Sinos. Foi organizada por esta entidade e contou com a presença de alunos e professores de escolas municipais de cidades onde estão as nascente do Rio dos Sinos, representantes do Centro de Estudos Ambientais (CEA) de Sapucaia, representantes da Secretaria de Meio Ambiente de 
Novo Hamburgo (SEMAN) e líderes religiosos da Igreja Católica, da Umbanda e da Igreja Luterana, além da participação de um fotógrafo e uma escritora que ali lançaram o livro "Sinuoso Rio dos Sinos". Parte do evento contou uma exposição de fotos na mesma Universidade, que intitulada "O Sinuoso", exibiu fotos de lugares e pessoas ao longo do referido rio.

No mini auditório da biblioteca, local do evento, um computador, data show, alguns instrumentos musicais e uma mesa com flores, um cálice e uma pequena imagem de Nossa Senhora Aparecida das Águas decoravam o espaço de apresentações. A sala, estava repleta de alunos uniformizados com camisetas de diferentes escolas municipais ou diferentes projetos de Educação Ambiental - dentre estes, Projeto Peixe Dourado e Projeto Conhecendo o Banhado, ambos de Estância Velha e o Projeto Resgatando Fontes de Vida, de Canoas - projeto pelo qual a Fonte Dona Josefina em Canoas foi revitalizada, evento comemorado na $17^{\mathrm{a}}$ Romaria das Águas. Todos projetos ligados à Educação Ambiental.

A abertura do evento foi feita pelo presidente do Comitê, que em seu discurso, fez menção à importância das nascentes do Rio dos Sinos e à importância da relação entre Comitê e sociedade civil, enfatizando que a Celebração das Águas propicia o encontro entre artes, religiões e crenças sobre a água, reificando uma celebração cultural, ecumênica, social e ambiental em detrimento de uma relação puramente econômica com a água, colocando em jogo interesses e necessidades específicas que tendem formar associações e à satisfazer aos interesses de grupo (Simmel, 1983), no caso deste, pensar e usar a água para além do viés econômico.

Neste evento, as amostras de águas foram trazidas pelos professores ou educadores ambientais que coordenam projetos nas escolas municipais participantes, por representantes da ONG CEA e por funcionários da SEMAM. Constituía parte do ritual, ao levar essa amostra até o cálice relatar, em breves palavras, sua vivência com as águas da Bacia dos Sinos. Grande parte desses relatos trouxeram as belezas naturais da região, denúncias de poluição, dragagem e assoreamento de rios e nascentes e uma súplica comum pela preservação das águas. Outros relatos trouxeram aspectos históricos da região, como a construção de pontes e moradias ao longo da Bacia Hidrográfica e outros relacionaram seus discursos a preces de "harmonia entre a Natureza e o Homem". História, ecologia e reverência ao elemento água.

Foram misturadas águas de catorze municípios que compõem a Bacia do Rio dos Sinos, Caraá, Santo Antônio da Patrulha, Taquara, São Francisco de Paula, Três Coroas, 
Parobé, Sapiranga, Campo Bom, Estância Velha, Novo Hamburgo, São Leopoldo, Sapucaia, Esteio e Canoas. Essas águas foram abençoadas numa celebração macroecumênica. A pastora da Igreja Luterana lembrou trechos da bíblia sobre água e associou-os à justiça, ao descanso e ao cuidado, à fonte de vida; o padre fez um sermão no qual "todos somos culpados e temos que melhorar" nossos atos com a água e a natureza. Por fim, a Mãe de Umbanda, associou água à vida e aos principais rituais de proteção, benção e purificação de sua religião. Não deixou de lembrar a preocupação recente de seu grupo com "oferendas ecológicas" e findou elevando o pensamento à “cultuação das águas”. “Águas abençoadas” seguimos em procissão, ao som do grupo "Som na Lata" - um projeto musical de Esteio que recicla materiais fazendo instrumentos musicais - até o Lago da Unisinos, ali jogou-se as águas e findou-se o evento.

Neste momento consegui conversar com a secretária executiva do COMITESINOS. De acordo com ela, este evento se chamou Romaria das Águas durante oito anos, todavia este ano, resolveram mudar o nome para dissolver o caráter religioso que palavra Romaria traz. Além disto, ela lembra que no ano passado, as disputas entre os líderes religiosos para decidir qual deles fariam a benção, influenciou bastante esta troca. Novamente é presente o conflito como elemento da própria relação que além de mantê-la, é constituinte dela, na medida em que a transforma também (Simmel, 1983).

Se toda interação é importante para aqueles que compartilham do mesmo interesse formarem suas unidades, suas sociedades de forma lúdica e/ou simbólica, sem “propósitos objetivos, nem conteúdos, nem resultados exteriores”. Se opor, é de alguma maneira se impor, sentir-se atuando e não apenas vítima das circunstâncias, o conflito não deixa de ser uma sociação que integra aspectos positivos e negativos. Ainda mais na vida urbana moderna, na qual as relações se baseiam em inúmeros contatos diários, dos simpáticos aos antipáticos, dos aversos aos indiferentes, dos efêmeros aos duradouros (Simmel, p.173). Na Romaria e na Celebração das Águas, os rituais que compõem sua socialidade - tanto de convivência, quanto de conflito - fundamentam o reencontrar-se de todos os anos, o rearranjar-se todos os anos e o habitus ecológico, que orienta suas crenças, simbologias e práticas cotidianas. 


\section{O habitus ecológico na Romaria das Águas}

De acordo com Norbert Elias (1994), o habitus pode ser entendido como a composição social dos indivíduos, como o componente no qual brotam as características pessoais de cada um, diferindo dos demais membros da sociedade, sendo simultaneamente objetivo e subjetivo. Para Pierre Bourdieu, este constitui um sistema de disposições duráveis e transponíveis que, integrando experiências passadas, funciona como uma matriz de percepções, de apreciações e de ações. E dessa maneira, pressupõe o domínio de um código comum, concordância e disposições entre os habitus dos agentes mobilizadores.

Na sociedade moderna, o habitus de grupo individualizado por um sujeito é complexo, e depende do número de planos interligados de sua sociedade, ou seja, é composto por diversas camadas, tendo uma delas especial proeminência (Elias, 1994). Ao mesmo tempo, nossa vida comunitária pode ser modificada segundo nossos processos de aprendizagem e é portanto, passível de desenvolvimento, o que a torna também um problema de habitus, "um traço básico da estrutura de personalidade social das pessoas da era moderna", tornando as muitas camadas do habitus, o aspecto multiestratificado do "nós". É a partir desses diferentes planos de integração que varia a intensidade de identificação do indivíduo - família, lugares, cidades, nações, etc.

Sendo assim, o habitus social que constitui o caráter nacional como formação social está na semelhança da língua solido e firme é também flexível e imutável (Elias, 1994). Neste trabalho, o habitus que constitui a subjetividade ecológica como formação social, está presente nas semelhantes práticas, discursos e rituais ecológicos e simbólicos sólidos e firmes, mas também na flexibilidade de aceitação e participação de agentes das outras camadas que o envolvem como a religião e a política.

Tal situação pode ser percebida a partir da observação de uma lidernça católica, ao me relatar que "este ano quem está puxando a Romaria é a Umbanda, mas se a natureza chama, como nós que somos natureza não vamos atender, né?”, deixando claro que mesmo com as várias camadas de planos que interligam a Romaria das Águas, a "natureza", a preocupação com as nascentes, com a água e a preservação ambiental é a proeminente. Da mesma maneira, o discurso das lideranças religiosas tanto na Romaria quanto na Celebração das Águas, remetem à esfera ecológica como o viés que os tornam associados a partir de discursos como: "ninguém quer falar da sua religião, mas do nosso bem maior que é a água", "a natureza e a ecologia como a bandeira dos religiosos", “agredir a natureza é agredir a nós mesmos", "lembrar a natureza como 
templo de Deus".

Outro ponto interessante foi levantado por uma liderança afro-umbandista na Celebração das Águas, que trouxe a questão das oferendas ecológicas. Rituais parte do cotidiano da Umbanda, que de acordo com o seu discurso, seus responsáveis têm o dever de "zelar pela água e prover o uso da mesma por gerações que ainda estão por vir".

De acordo com Michel Maffesoli (2000: 31) o habitus remete ao banal, à vida de todos os dias, ao costume e é justamente esse costume, esse habitus, que fundamenta o "estar-junto" em conjunto. O sentir comum, a sensibilidade coletiva é o que suscita condições para uma espécie de "aura" que particulariza tal grupo ou tal época, a "aura estética" do grupo, ou seja, o reencontro dos elementos que nos remetem a uma pulsão comunitária. Considerada um misto de objetividade e subjetividade, essa sensibilidade, que se conjugam para produzir uma vida cotidiana e é exatamente esta sinergia que produz a sociedade complexa que compartilhamos. "É essa emoção que cimenta um conjunto" que, mesmo com a pluralidade de elementos disponíveis, compartilha uma ambiência específica que os torna solidários uns com os outros. A estética do sentimento é justamente esta abertura para os outros, para o Outro. Desta forma, o habitus ou o costume servem para concretizar, para atualizar a dimensão ética - laço coletivo - de toda socialidade. Como acontece com o habitus ecológico na Romaria das Águas.

Outro ponto importante na continuidade dos processos sociais (Elias, 1994) ou nas "correntes de experiências" (Maffesoli, 2000) do que é vivido "são os quadros da memória coletiva" (Maurice Halbwachs, 2004), pois é a dimensão sensível do conhecimento que permite "nascer junto" enraizado nos costumes. Só a continuidade da memória é capaz de preservar os conhecimentos e as experiências pessoais adquiridos em fases anteriores, embora até mesmo esta memória possa se modificar a medida em que as pessoas amadurecem ou envelhecem (Elias, 1994).

Assim, mesmo com poucos dados sobre essa memória coletiva que permeia e que permite a continuidade da Romaria das Águas, um breve histórico deste movimento, mostra que este iniciou-se, expandiu-se e mantém-se via discursos e práticas ecológicas associadas à práticas religiosas, de educação ambiental ou políticas. A simbologia do encontro de Nossa Senhora Aparecida quebrada no meio do lixo a ser reciclado em Arquipélago, envolve questões simbólicas da ordem do cotidiano. E como lembra Michel Maffesoli (2000: 38) “é bom lembrar que o divino é oriundo das realidades cotidianas, que ele se elabora pouco a pouco na partilha dos gestos simples e 
rotineiros", atualizando o laço coletivo que envolve essa socialidade.

Ainda cabe lembrar, que a própria dinâmica de incluir relatos de vivências junto à Bacia dos Sinos durante a Celebração das Águas, concretiza o sentir comum e a formação de um laço coletivo - respectivamente, estético e ético (Maffesoli, 2000) através da memória individual que naquele momento é compartilhada, acionando um habitus ecológico inscrito num ritual religioso que se expande em práticas educativas e políticas. É neste sentido que, o habitus ecológico que permeia a Romaria das Águas e depende dos diversos planos interligados, é composto por muitas camadas e um "nós" multiestratificado entre as esferas da religião, da política e da educação ambiental. Sendo a memória coletiva, “a visão de dentro" (Halbwachs, 2004) o elemento que mantém a continuidade desse movimento via sensibilidade coletiva e domínio do código comum da ecologia.

\section{Apontamentos finais}

Este trabalho pretendeu uma incursão inicial no estudo das relações entre Ecologia e Religião na Romaria das Águas, além de outras esferas que circundam a questão, como Educação e Política. Pretendo ter demonstrado aqui como essa relação se dá entre as camadas que interligam diversos planos de integração, mas com uma proeminente, o habitus ecológico, proporcionando uma pulsão comunitária no cuidado com o Lago Guaíba manifestada em diferentes formas de sociabilidade.

Ao perceber que as formas de sociabilidade tanto de convivência quanto de conflito entre os participantes da ritualização do elemento água em questão se intercalavam entre a sacralização, a proteção e denúncia, o cuidado e a renovação e a ação política em torno de nascentes, rios e lagos, pude me referenciar no conceito de habitus para entender a composição individual e a composição social desse grupo, os componentes objetivo e subjetivo de ambos e enfatizar as camadas entrelaçadas que interligam esse habitus aos diversos planos da sociedade deixando um destes proeminentes (Bourdieu, 1983, Elias, 1994).

Ao identificar o habitus ecológico como o principal fator de associação, me apoiei em Michel Maffesoli (2000) para dar conta de quais os princípios desse habitus, por ele chamado costume, que concretizam a pulsão comunitária, o sentir comum. Identifiquei nos rituais simbólicos de despoluição, nas ações políticas de proteção e na reverência à água pontos comuns que dão a linha para que a preocupação com o meio ambiente tenha se tornado parte do habitus ou costume da Romaria ou Celebração das 
Águas. Nesse sentido, o sentido ecológico da Romaria ou da Celebração permite uma esfera comum, onde todos os preocupados com poluição e cuidado em torno do meio ambiente estão ligados, ao mesmo tempo em que o caráter inter-religioso permite que as diferenças apresentadas e respeitadas.

Ainda timidamente, pude trazer alguns elementos da memória coletiva (Halbwachs, 2004) que remontam a experiência e a continuidade desse processo a partir da reconstrução constante de sua história, dos espaços e práticas que se mantém, como os galpões de reciclagem de lixo no Arquipélago, Nossa Senhora Aparecida reconstituída manualmente em exposição e a associação da experiência de cada um com a água como parte do discurso e do ritual. Além disto, o próprio fato de envolver crianças no projeto, denota esse desejo de continuidade.

Por fim, procuro identificar aqui como o habitus ecológico que permeia as esferas religiosas, políticas e educacionais proporcionam uma pulsão comum entre grupos diversos e desencadeiam formas de sociabilidade comum no cuidado com o Lago Guaíba, mais especificamente, os rituais de peregrinação e de coleta, benção e mistura de águas na $17^{a}$ Romaria das Águas e a Celebração das Águas 2010.

\section{Referências}

BOURDIEU, Pierre. Pierre Bourdieu. São Paulo: Editora Ática, 1983.

CARVALHO, I. C. M. \& STEIL, C. A. "O habitus ecológico e a educação da percepção: fundamentos antropológicos para a educação ambiental”. In: Educação \& Realidade, v. 34, n. 3. Porto Alegre: UFRGS, 2009.

CHAVES, Christine de Alencar. "A marcha nacional dos Sem Terra: estudo de um ritual político". In: PEIRANO, Mariza (org.). O dito e o feito: ensaios de antropologia dos rituais. Rio de Janeiro: Relume Dumará. Núcleo de Antropologia da Política/UFRJ, 2002.

ELIAS, Norbert. A sociedade dos indivíduos. Rio de Janeiro: Jorge Zahar, 1994.

FAUERS. Federação Afro-Umbandista e Espiritualista do RS. Disponível em: www.fauers.com.br. Acessado em: 22 de agosto de 2010.

HALBWACHS, Maurice. A memória coletiva. São Paulo: Vértice, 1990.

LEACH, Edmund. Sistemas Políticos da Alta Birmânia. São Paulo: Ed. da Universidade de São Paulo, 1996.

MAFFESOLI, Michel. O tempo das tribos, o declínio do individualismo nas sociedades de massa. Rio de Janeiro: Forense Universitária, 1987.

MORAES FILHO, Evaristo. (Org.). Simmel. São Paulo: Editora Ática, 1983.

PACHECO, M.I.; SOARES, N., PAVELACKI, J.A. Cartilha da $15^{\mathrm{a}}$ Romaria das Águas. Material Impresso, 2008.

PEIRANO, Mariza (org.). O dito e o feito: ensaios de antropologia dos rituais. Rio de Janeiro: Relume Dumará. Núcleo de Antropologia da Política/UFRJ, 2002. 
ROMARIA DAS ÁGUAS. Disponível em: www.romariadasaguasguaiba.blogspot.br. Acessado em: 25 de agosto de 2010.

Recebido em: 19/12/2010

Aprovado em: 28/03/2011 